\title{
Expression of MAGE-A12 in oral squamous cell carcinoma
}

\author{
Nur Mollaoglu ${ }^{\mathrm{a}, \mathrm{b}, *}$, Eleftherios Vairaktaris ${ }^{\mathrm{c}}$, Emeka Nkenke $^{\mathrm{a}}$, Friedrich W. Neukam ${ }^{\mathrm{a}}$ and Jutta Ries ${ }^{\mathrm{a}}$ \\ ${ }^{a}$ Department of Oral and Maxillofacial Surgery, Friedrich-Alexander University of Erlangen/Nuremberg, \\ Glückstrasse 11, 91054, Erlangen, Germany \\ ${ }^{\mathrm{b}}$ Department of Oral and Maxillofacial Surgery, Gazi University, School of Dentistry, Emek 8.Cadde, 82.sokak, \\ No:4, 06510, Ankara, Turkey \\ ${ }^{\mathrm{c}}$ Department of Oral and Maxillofacial Surgery, University of Athens Medical School, Attikon Hospital, Rimini 1, \\ GR 12462, Greece
}

\begin{abstract}
Melanoma associated-A antigens (MAGE-A) are silent in normal tissues except testis. However, they are activated in a variety of different tumors. Thus, their expression is highly specific to cancer cells. Reverse transcription-nested polymerase chain reaction (RT-nPCR) is a highly sensitive technique that has been used successfully for the detection of MAGE genes in tissue samples. The aim of the study is to analyze the expression rate of MAGE-A12 in oral squamous cell carcinoma (OSCC) using a high sensitive RT-nPCR. Total of 57 tissue samples obtained from patients with OSCC and 20 normal oral mucosal (NOM) probes of otherwise healthy volunteers were included to this study. No expression of MAGE-A12 was observed in the non-neoplastic NOM tissues. MAGE-A12 was expressed in $49.1 \%$ of the investigated tumor samples. The correlation between malignant lesion and MAGE-A12 detection was significant $(p<0.001)$. It is concluded that results of this study may indicate MAGE-A12 as a useful additional diagnostic marker especially for the early detection of OSCC distinguishing neoplastic transformation and detection of occult and/or rare disseminated cancer cells. In addition, MAGE-A12 expression in OSCC may also determine a new immunotherapeutic target and might be warranted to develop vaccine for OSCC.
\end{abstract}

Keywords: Nested RT-PCR, MAGE-A12 gene expression, oral squamous cell carcinoma, diagnostic, therapy

\section{Introduction}

Oral squamous cell carcinoma (OSCC) is the $6^{\text {th }}$ most common cancer worldwide accounting for 3-5\% of all malignancies [13]. Although, the early stage of OSCC is often curable, the prognosis of advanced cases generally remains poor. Oral cancer has been known to exhibit "field cancerization" that may cause a secondary primary tumor varying between $4.3 \%$ and $30 \%$ [6]. The local recurrence of OSSC might have been seen due to the existence of occult cancer cells in tumor mar-

*Corresponding author: Assoc. Prof. Nur Mollaoglu, University of Erlangen/Nuremberg, Department of Oral and Maxillofacial Surgery, Glückstrasse 11, 91054, Erlangen, Germany. Tel.: +499131 85 4230; Fax: +49 913185 4219; E-mail: nurmolla@gazi.edu.tr, Nur.Mollaoglu@mkg.imed.uni-erlangen.de. gins. In such cases, early detection and/or treatment of oral cancer can significantly improve the survival rate. Therefore, estimation of recurrency or the premalignant stage of a secondary primary tumor using a high specific tumor associated marker to differentiate malignant from a benign might be of important. Despite the diagnostic and therapeutic advances in combination therapy including surgery, radiation and chemotherapy, the prognosis of OSCC remains still 50\%-60\% in five year survival analysis and has not been changed significantly during the last three decades [23]. New therapeutic strategies are actively pursued one of the most popular immunotherapy. Active immunotherapy approaching malignant cells by using vaccines derived from defined antigens appeared to be especially attractive to treat OSCC. Prerequisites for the development of specific vaccines are the existence and identification 
of genes that are exclusively or preferentially expressed in malignant tissues compared to normal tissues.

Melanoma associated-A antigens (MAGE-A) are expressed in a variety of different tumors and their detection is highly specific to cancer cells. The human MAGE-A gene family consists of 12 members including MAGE-A1-A12 and encodes products that can be recognized by autologous cytotoxic T(CT) cells. These genes are silent in normal tissues except testis but are activated in a variety of neoplastic lesions. These neoplastic and immunogenic features made MAGE an attractive target for cancer detection and also for immunotherapy [3,7,11]. It has been previously reported that MAGE-A12 is expressed in esophageal, cervical and breast cancer $[1,10,17]$.

Reverse transcription-nested polymerase chain reaction (RT-nPCR) used for the detection of MAGE-A12 is a highly sensitive technique developed by Kufer et al. [24]. This method has been successfully utilized in detection of disseminated tumor cells in blood and bone marrow when used in combination with the detection of other tumor-associated antigens in patients suffering from breast, lung, colorectal and prostate cancer. Furthermore, there are numerous studies on the expression of the MAGE-A gene family members in head and neck carcinomas and oral cancer $[11,12,16]$. However, there has been only one study that has been reported the expression of MAGE-A12 in HNSCC including relatively small amount of samples $(n=29)$ including only 15 OS$\mathrm{CC}$ specimens [5]. Therefore, we aimed to analyze the expression frequency and pattern of MAGE-A12 only in relatively larger amount of OSCC samples using a high sensitive RT-nPCR.

\section{Materials and methods}

\subsection{Tissues and cell lines}

Total of 57 tissue samples obtained from patients with OSCC and 20 normal oral mucosal (NOM) probes of otherwise healthy volunteers were included to this study following the approval by the Ethics Committee of Friedrich Alexander University ErlangenNuremberg, Germany. All the OSCC samples were obtained from surgical specimens collected during tumor surgery. Prior to our investigation tumor staging has been done for all the samples according to TNM classification of International Union Against Cancer (UICC) by both clinically and pathologically [25]. Patients have received neither radiotherapy nor chemotherapy prior to biopsy or tumor resection. Collection and storage of the tissue samples were done carefully in the same manner. Each sample was divided into two pieces. First piece was used for histological examination. The second piece was immediately snap frozen and stored at $-80^{\circ} \mathrm{C}$ until examination. Patients were followed up clinically in regular intervals. For RTnPCR analysis, RNA extracted from normal colon and human foreskin fibroblasts (HFF) were used as negative controls. In addition, human melanoma cell line (Gerl 43) (G) and tissue of testis (T) were used as positive controls (Fig. 1).

\section{2. $R T-n P C R$ for $M A G E A 12$}

A high sensitive RT-nPCR for detection of MAGEA12-expressing tissues was used. In summary, total RNA from frozen tissues and cells were isolated using Rneasy Mini Kit according to the manufacturer's instructions (Qiagen, Hilden).

\subsection{Reverse transcription and first PCR amplification step}

200ng of total RNA were used for the detection of the expression of MAGE-A12 gene. Reverse transcription and the first PCR reaction were carried out using One Step RT-PCR Kit (Qiagen, Hilden) using outer MAGE primers (Table 1). Cycling conditions were as follows: Reverse transcription was done at $50^{\circ} \mathrm{C}$ for $30 \mathrm{~min}$. Initial PCR activation step was performed at $95^{\circ} \mathrm{C}$ for $5 \mathrm{~min}$, followed by 30 cycles of $95^{\circ} \mathrm{C}$ for $30 \mathrm{~s}, 60^{\circ} \mathrm{C}$ for $45 \mathrm{~s}$, and $72{ }^{\circ} \mathrm{C}$ for $45 \mathrm{~s}$. The final extension incubation was performed at $72^{\circ} \mathrm{C}$ for $10 \mathrm{~min}$.

\subsection{Nested PCR}

For the second round of PCR, $1 \mu \mathrm{l}$ of the first reaction, $1 \mu 1$ of 10x PCR buffer [100 mM Tris ( $\mathrm{pH} 8.3$ ), $500 \mathrm{mM} \mathrm{KCl}, 10 \mathrm{mM} \mathrm{MgCl} 2,1 \mathrm{mM}$ deoxynucleotide triphosphate], $0.4 \mu \mathrm{M}$ each of the inner MAGE primers (Table 1), $5 \mu \mathrm{g}$ of BSA (Roche), and 0.6 units of Taq DNA Polymerase were run according to the following cycle profile: an initial denaturation at $94{ }^{\circ} \mathrm{C}$ for 10 min to activate the enzyme, followed by $94^{\circ} \mathrm{C}$ for $40 \mathrm{~s}$, annealing at $58^{\circ} \mathrm{C}$ for $30 \mathrm{~s}$, and elongation at $72^{\circ} \mathrm{C}$ for $30 \mathrm{~s}$ for 30 cycles and a final extension at $72^{\circ} \mathrm{C}$ for $2 \mathrm{~min}$. PCR products were separated on a $1.5 \%$ agarose gel and stained with ethidium bromide. The size of the fragment amplificated by RT-PCR is $181 \mathrm{bp}$ (Fig. 1) (Table 1). Only the amplificated fragments in 
Table 1

Primer amplification of MAGE-A12

\begin{tabular}{llccc}
\hline Primer & Primer sequence & $\begin{array}{c}\text { Cycle number } \\
\text { number }\end{array}$ & $\begin{array}{c}\text { Size } \\
\text { product bp. }\end{array}$ & $\begin{array}{c}\text { Annealing } \\
\text { temperature }\end{array}$ \\
\hline MAGE-A12os & TCCGTGAGGAGGCAAGGTTC & 30 & 341 & 60 \\
\hline MAGEA12oas & ATCGGATTGACTCCAGAGAGTA & & & \\
MAGE-A12is & TCCGTGAGGAGGCAAGGTTC & 30 & 181 & 58 \\
MAGEA12ias & GAGCCTGCGCACCCACCAA & & & \\
\hline
\end{tabular}

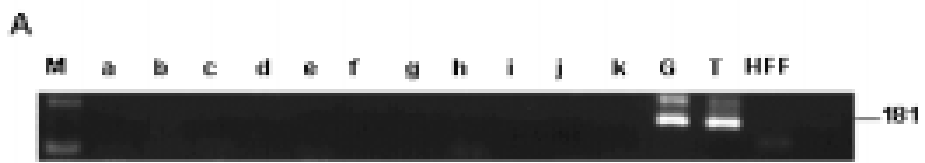

B
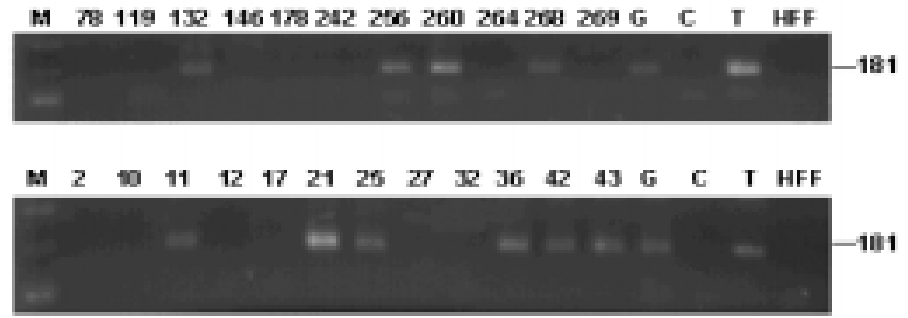

Fig. 1. Expression analysis of MAGE-A12 by RT-nPCR. A: Expression in normal tissue (samples a-k are all obtained from otherwise healthy volunteers); B: Expression in OSCC (samples 2-269 are all obtained from patients with OSCC); $(+)$ and $(-)$ controls: G: human melanoma cell line (+), T: Testis (-); HFF: human foreskin fibroblasts (-); M: Marker.

size of $181 \mathrm{bp}$ have been estimated as positive. The positive and negative results were confirmed by running the assay for both results with a second aliquot of each original total RNA sample.

\subsection{Statistical analysis}

The statistical software package SPSS 14.0 (Inc., Chicago, USA) was used. The prevalence of MAGEA12 mRNA expression in cancers and normal tissues was compared by Chi Square test. The association between MAGE-A12 mRNA expression in tumors and various clinicopathological variables was also examined by Chi Square test and Fisher's exact test. P value less than 0.05 indicated statistical significance.

\section{Results}

Total of 57 specimens from OSCC to determine the MAGE-A12 expression profile and 20 specimens from NOM taken from otherwise healthy volunteers were analysed. MAGE-A12 expression was restricted to neoplastic specimens. Fourty-eight of 57 OSCC patients were female and nine of them were female with a mean age of 58.5 years old (Min:34 and Max:91). The percentage of the positive expression of tumor samples is $49.1 \%$. The correlation between malignant lesions and MAGE-A12 detection was statistically significant $(p<0.001)$ (Table 2). Tumor classification, staging, grading and lymph node status of the 57 specimens from OSCC were displayed in Table 2. The relationship between the expression of the analysed MAGEA12 and different clinicopathological factors were statistically evaluated. Statistical differences between the MAGE-A12 expression and these parameters of OSCC were not statistically significant $(p>0.05)$ (Table 2$)$.

Of the 57 tumor cases studied, 16 (37.5\%) had histological characteristics of well-differentiated tumors, $35(60 \%)$ were moderately differentiated, and three $(33.3 \%)$ were poorly differentiated. No correlation was observed between gene expressions and grading of tumor (Table 2).

Staging of tumors and the expression of MAGEA12 were as follows; T4 displayed $45 \%$ expression of MAGE-A12 in OSCC samples, T3 displayed 75\%, T2 
Table 2

Correlation between expression of MAGE-A12 and clinicohistopathologica parameters ( $\mathrm{p}$ value related to diagnosis)

\begin{tabular}{lrrrcr}
\hline & Total & $(+)$ & $(-)$ & expression $(\%)$ & p-value \\
\hline Nr. of cases & 57 & 28 & 29 & 49.1 & $<\mathbf{0 . 0 0 1}$ \\
Grading & & & & & 0.264 \\
$\quad$ G1 & 3 & 1 & 2 & 33.3 & \\
G2 & 35 & 21 & 14 & 60 & \\
G3 & 16 & 6 & 10 & 37.5 & \\
Tumor size & & & & & 0.528 \\
$\quad 1$ & 18 & 10 & 8 & 55.6 & \\
2 & 11 & 4 & 7 & 36.4 & \\
3 & 4 & 3 & 1 & 75 & \\
4 & 20 & 9 & 11 & 45 & \\
State of lymph node & & & & & \\
0 & 27 & 17 & 10 & 63 & \\
1 & 8 & 2 & 6 & 25 & \\
2 & 12 & 4 & 8 & 33.3 & \\
State of lymph node & & & & & \\
$\quad$ N0 & 27 & 17 & 10 & 63 & \\
N $>0$ & 20 & 6 & 14 & 58.3 & \\
Stage & & & & & \\
Early (I, II) & 25 & 13 & 12 & 52 & 0.685 \\
Late (III, IV) & 28 & 13 & 15 & 46.4 & \\
I & 17 & 11 & 6 & 64.7 & 0.257 \\
II & 8 & 2 & 6 & 25 & \\
III & 5 & 3 & 2 & 60 & \\
IV & 23 & 10 & 13 & 43.5 & \\
\hline
\end{tabular}

\footnotetext{
*Analysed by Fisher's exact test. The rest have been analysed by Chi Square test.

The number of missing cases for Grading: 3; Tumor size: 4; State of lymph node: 10 ; Stage: 4.
}

displayed $36.4 \%$ and $\mathrm{T} 1$ displayed $55.6 \%$ respectively. Expression rate was highest in stage T3. However, there was no statistical significance found between staging and expression of MAGE-A12 (Table 2). In addition, no correlation was observed between gene expressions and state of lymph node when N0 was compared by $\mathrm{N} 1$ and $\mathrm{N} 2$ separately $(p>0.05)$. However, there was a statistical significance when N0 was compared by $\mathrm{N} 1+\mathrm{N} 2$ together $(\mathrm{N} 0<\mathrm{N} 1+\mathrm{N} 2)(p<$ 0.05) (Table 2).

\section{Discussion}

The expression of different subtypes of MAGE-A genes has been extensively studied in adult individual neoplasia arising from epithelial cell like melanoma, lung, bladder, breast, colorectal, gastric, esopharyngial SSC, hepaticellular carcinoma and head \& neck cancer $[5,9,12,16,21]$. However, there are only a few papers reporting the expression of MAGE-A genes in OSCC $[5,11]$. In the present study, MAGE-A12 was expressed in $49.1 \%$ of tumor samples diagnosed as OSCC. In addition, expression of MAGE-A12 was signif- icantly correlated to malignancy which may indicate its diagnostic excellence $(p<0.001)$. Previous studies have also reported positive expression of MAGEA12 in different types of tumors. The expression of MAGE-A12 was $26.7 \%$ in oesophageal tumor, $9 \%$ in breast cancer and $9.1 \%$ in HNSCC $[5,10,17]$. Our result indicates that MAGE-A12 is expressed by a higher frequency in OSSCs compared to other types of solid tumors and it might be a promising target for antigenspecific immunotherapy for OSCC. The reasons of high expression frequency of MAGE-A12 in OSCC might because of two reasons. First the oral cavity may express MAGE-A12 more than other types of tumors and second RT-nPCR is more sensitive than RT-PCR so expression frequency would automatically expected to be higher in our samples compared to previous reports [5, $10,17]$.

The function of MAGE proteins and their involvement in tumor progression have not been well explained yet. MAGE-A12 is reported to be reactivated mostly in early stages of carcinogenesis. Its expression follows demethylation which is an early hallmark in cancer prognosis to distinguish normal from neoplastic tissues [4]. In the present study, MAGE-A12 gene was 
expressed $52 \%$ in the early clinical stage and $46.4 \%$ in the late clinical stage when clinical stages of I and II were combined as early stage and stage III and IV as late stage. The late clinical stage reactivation might display that MAGE-A12 expression rate does not increase by the advancement of tumor stage indicating that expression of MAGE-A12 may be an early event in oral carcinogenesis. In addition, there found to be no significant association between any of the clinical parameter and mRNA expression of MAGE-A12. However, when state of lymph nodes, N1 and N2 grouped together as $\mathrm{N}$, there is a significant difference lying between $\mathrm{N} 0$ and $\mathrm{N}$ as $\mathrm{N}>\mathrm{N} 0$. Thus, grouping the lymph node state may be more advisable for MAGEA12 expression. Furthermore, higher proportion of MAGE-A12 expression among N0 cases may sign, that cases without MAGE-A12 expression may have higher propensity for lymph node metastasis and be short of immuno-recognition which hinders tumor progression.

MAGE genes are currently of great interest for the development of a vaccine against cancer. It has been already established that there are some peptides derived from MAGE-A12 that can induce CT cell immunresponce $[14,18]$. MAGE gene products are of particular interest in immunotherapy owing to their wide expression in many tumors and their potential to induce HLA class I mediated tumor-specific CTL responses [19,20, $22,26]$. It was suggested that autologous dendritic cells vaccination with MAGE-3 peptide is a safe and promising approach in the treatment of specific carcinomas depending on the patient's HLA haplotype (HLA-A2 or A24) $[2,8,26]$. It has been already known that both MAGE-3 and 12 peptides bind HLA-A2 [16]. Therefore, MAGE-A12 may be employed as a potential target for tumor-specific immunotherapy in OSCC. The successful development of antigen-specific vaccines against cancer depends on the identification of the appropriate target antigens. Results of the present study display a frequent expression of MAGE-A12 in OSCC. This finding may suggest that patients with OSCC can be a potential target for immunotherapy using "cancer vaccines" and/or using antibodies pointed against the antigen that carried specifically by the OSCC cells such as MAGE-A12.

In conclusion, results of this study may indicate MAGE-A12 as a useful additional diagnostic marker especially for the early detection of OSCC distinguishing neoplastic transformation and also detection of occult and/or rare disseminated cancer cells. In addition, monitoring of MAGE-A12 expression in OSCC may also determine a new immunotherapeutic target and might be warranted to develop OSCC vaccine.

\section{Acknowledgement}

This work has been supported by Deutsche Forschungsgemeinschaft (DFG)-The Scientific and Technological Research Council of Turkey (TÜBITAK), and by Johannes and Frieda Marohn Stiftung.

\section{References}

[1] B. Sarcevic, G.C. Spagnoli, L. Terracciano, E. Schultz-Thater, M. Heberer, M. Gamulin, Z. Krajina, T. Oresic, R. Separovic and A. Juretic, Expression of cancer/testis tumor associated antigens in cervical squamous cell carcinoma, Oncology 64 (2003), 443-449.

[2] B. Schuler-Thurner, D. Dieckmann, P. Keikavoussi, A. Bender, C. Maczek, H. Jonuleit, C. Roder, I. Haendle, W. Leisgang, R. Dunbar, V. Cerundolo, P. von Den Driesch, J. Knop, EB. Brocker, A. Enk, E. Kampgen and G. Schuler, Mage3 and influenza-matrix peptide-specific cytotoxic $\mathrm{T}$ cells are inducible in terminal stage HLA-A2.1+ melanoma patients by mature monocyte-derived dendritic cells, J Immunol 165 (2000), 3492-3496.

[3] B.P. Van Der Bruggen, C. Traversari, P. Chomez, C. Lurquin, E. De Plaen, E.B. Van den, A. Knuth and T. Boon, A gene encoding an antigen recognized by cytolytic $\mathrm{T}$ lymphocytes on a human melanoma, Science 254 (1991), 1643-1647.

[4] C. De Smet, C. Lurquin, B. Lethe, V. Martelange and T. Boon, DNA methylation is the primary silencing mechanism for a set of germ line- and tumor-specific genes with a CpG-rich promoter, Mol Cell Biol 19 (1999), 7327-7335.

[5] D.L. Figueiredo, R.C. Mamede, R. Proto-Siqueira, L. Neder, W.A. Silva Jr and M.A. Zago, Expression of cancer testis antigens in head and neck squamous cell carcinomas, Head Neck 28 (2006), 614-619.

[6] D.P. Slaughter, "Field cancerization" in oral stratified squamous epithelium: Clinical implications of multicentric origin, Cancer 6 (1953), 963-968.

[7] E. De Plaen, K. Arden, C. Traversari, J.J. Gaforio, J.P. Szikora, C. De Smet, F. Brasseur, P. Van der Bruggen, B. Lethe, C. Lurquin et al., Structure, chromosomal localization, and expression of 12 genes of the MAGE family, Immunogenetics 40 (1994), 360-369.

[8] E.S. Schultz, B. Schuler-Thurner, V. Stroobant, L. Jenne, T.G. Berger, K. Thielemanns, P. van der Bruggen and G. Schuler, Functional analysis of tumor-specific The cell responses detected in melanoma patients after dendritic cell-based immunotherapy, J Immunol 172 (2004), 1304-1310.

[9] G. Luo, S. Huang, X. Xie, E. Stockert, Y.T. Chen, B. Kubuschok, M. Pfreundschuh, Expression of cancer-testis genes in human hepatocellular carcinomas, Cancer Immunity 2 (2002), 11-20.

[10] J. Lin, L. Lin, D.G. Thomas, J.K. Greenson, T.J. Giordano, G.S. Robinson, R.A. Barve, F.A. Weishaar, J.M. Taylor, M.B. Orringer and D.G. Beer, Melanoma-associated antigens in esophageal adenocarcinoma: identification of novel MAGEA10 splice variants, Clin Cancer Res 17 (2004), 5708-5716.

[11] J. Ries, S. Schultze-Mosgau, F. Neukam, E. Diebel and J. Wiltfang, Investigation of the expression of melanoma antigenencoding genes (MAGE-A1 to-A6) in oral squamous cell carcinomas to determine potential targets for gene-based cancer immunotherapy, Int J Oncol 26 (2005), 817-824. 
[12] J.W. Park, T.K. Kwon, ich. Kim, S.S. Sohn, Y.S. Kim, C.I. Kim, O.S. Bae, K.S. Lee, K.D. Lee, C.S. Lee, H.K. Chang, B.K. Choe, S.Y. Ahn and C.H. Jeon, A new strategy for the diagnosis of MAGE-expressing cancers, J Immunol Methods 266 (2002), 79-86.

[13] K.D. Hunter, E.K. Parkinson and P.R. Harrison, Profiling early head and neck cancer, Nat Rev Cancer 2 (2005), 127-135.

[14] L. Heidecker, F. Brasseur, M. Probst-Kepper, M. Gueguen, T. Boon and B.J. Van den Eynde, Cytolytic T lymphocytes raised against a human bladder carcinoma recognize an antigen encoded by gene MAGE-A12, J Immunol 164 (2000), 60416045.

[15] M. Ding, R.J. Beck, C.J. Keller and R.G. Fenton, Cloning and analysis of MAGE-1-related genes, Biochem Biophys Res Commun 202 (1994), 549-555.

[16] M. Eura, K. Ogi, K. Chikamatsu, K.D. Lee, K. Nakano, K. Masuyama, K. Itoh and T. Ishikawa, Expression of the MAGE gene family in human head-and-neck squamous-cell carcinomas, Int J Cancer 64 (1995), 304-308.

[17] M. Otte, M. Zafrakas, L. Riethdorf, U. Pichlmeier, T. Loning, F. Janicke and K. Pantel, MAGE-A gene expression pattern in primary breast cancer, Cancer Res 15 (61) (2001), 6682-6687.

[18] M.C. Panelli, M.P. Bettinotti, K. Lally, G.A. Ohnmacht, Y. Li, P. Robbins, A. Riker, S.A. Rosenberg and F.M. Marincola, A tumor-infiltrating lymphocyte from a melanoma metastasis with decreased expression of melanoma differentiation antigens recognizes MAGE-12, J Immunol 164 (2000), 43824392.

[19] M.J. Scanlan, A.J. Simpson and L.J. Old, The cancer/testis genes: review, standardization, and commentary, Cancer Immun 4 (2004), 1-15.
[20] M.J. Scanlan, A.O. Gure, A.A. Jungbluth, L.J. Old and Y.T. Chen, Cancer/testis antigens: an expanding family of targets for cancer immunotherapy, Immunol Rev 188 (2002), 22-32.

[21] M.S. Park, J.W. Park, C.H. Jeon, K.D. Lee and H.K. Chang, Expression of melanoma antigen-encoding genes (MAGE) by common primers for MAGE A1 to A6 in colorectal carcinomas among Koreans, J Korean Med Sci 17 (2002), 497-501.

[22] N. Sadanaga, H. Nagashima, K. Mashino, K. Tahara, H. Yamaguchi, M. Ohta, T. Fujie, F. Tanaka, H. Inoue, K. Takesako, T. Akiyoshi and M. Mori, Dendritic cell vaccination with MAGE peptide is a novel therapeutic approach for gastrointestinal carcinomas, Clin Cancer Res 7 (2001), 2277-2284.

[23] O. Bettendorf, J. Piffko and A. Bankfalvi, Prognostic and predictive factors in oral squamous cell cancer: important tools for planning individual therapy? Oral Oncol 40 (2004), 110-119.

[24] P. Kufer, A. Zippelius, R. Lutterbuse, I. Mecklenburg, T. Enzmann, A. Montag, D. Weckermann, B. Passlick, N. Prang, P. Reichardt, M. Dugas, M.W. Kollermann, K. Pantel and G. Riethmuller, Heterogeneous expression of MAGE-A genes in occult disseminated tumor cells: a novel multimarker reverse transcription-polymerase chain reaction for diagnosis of micrometastatic disease, Cancer Res 62 (2002), 251-261.

[25] S.G. Patel and J.P. Shah, TNM staging of cancers of the head and neck: striving for uniformity among diversity, CA Cancer $J$ Clin 55 (2005), 242-258.

[26] X. Hao, Y. Shao, X. Ren, H. Liu, Q. Xu, H. Li, P. Zhang, $X$. An and B. Ren, Induction of specific CTL by MAGE3/CEA peptide-pulsed dendritic cells from HLA-A2/A24(+) gastrointestinal cancer patients, J Cancer Res Clin Oncol 128 (2002), 507-515. 


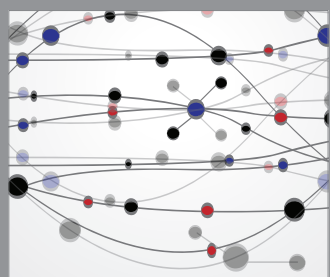

The Scientific World Journal
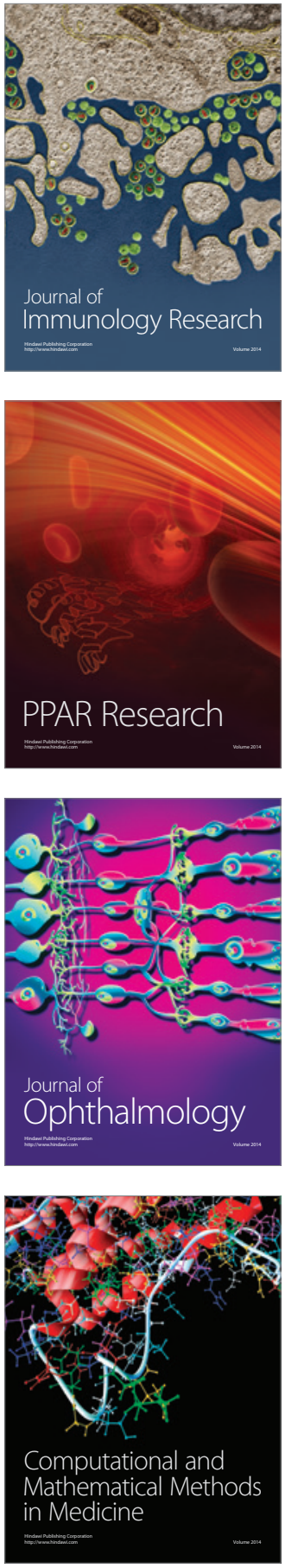

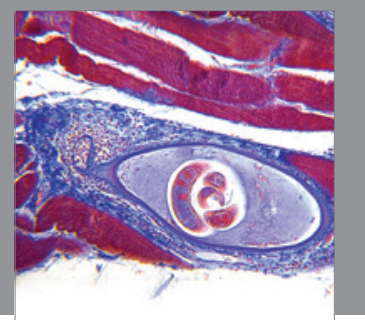

Gastroenterology

Research and Practice
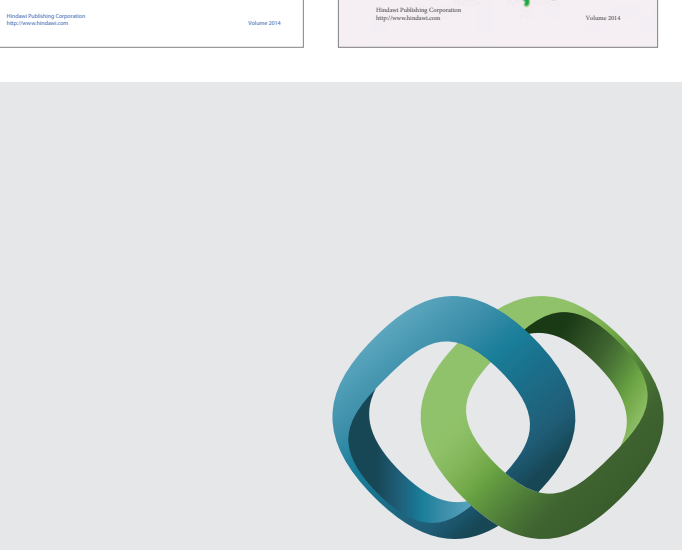

\section{Hindawi}

Submit your manuscripts at

http://www.hindawi.com
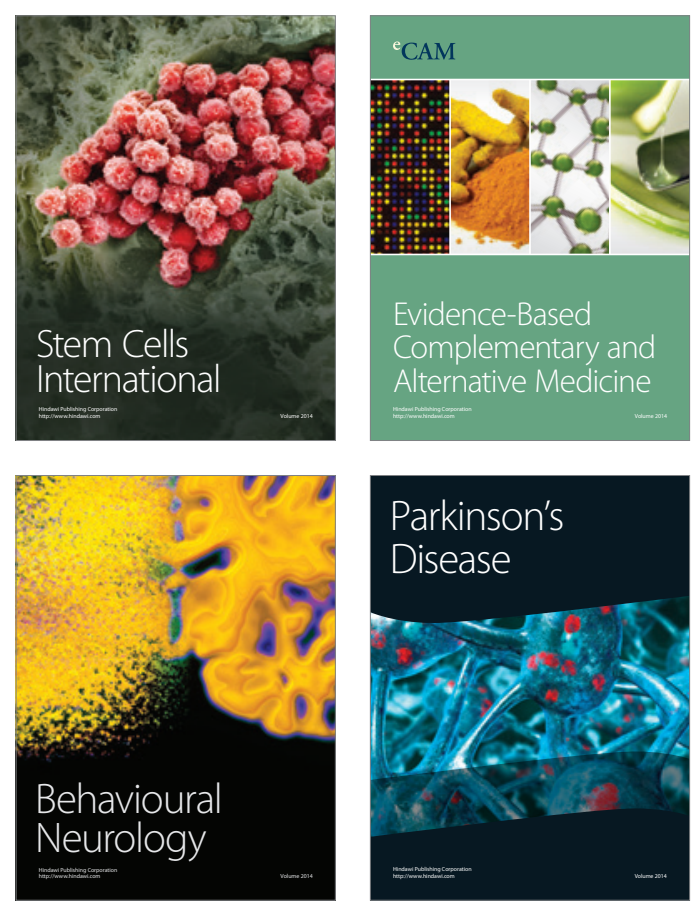

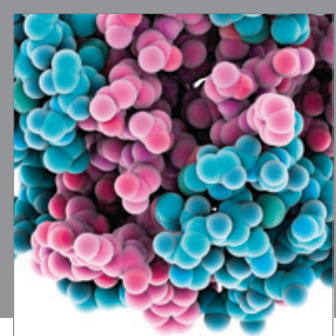

Journal of
Diabetes Research

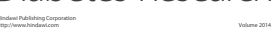

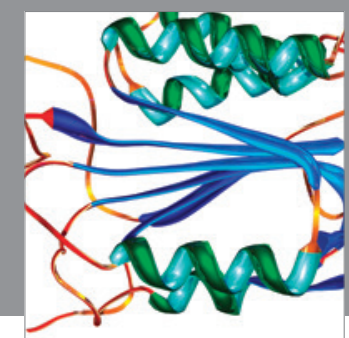

Disease Markers
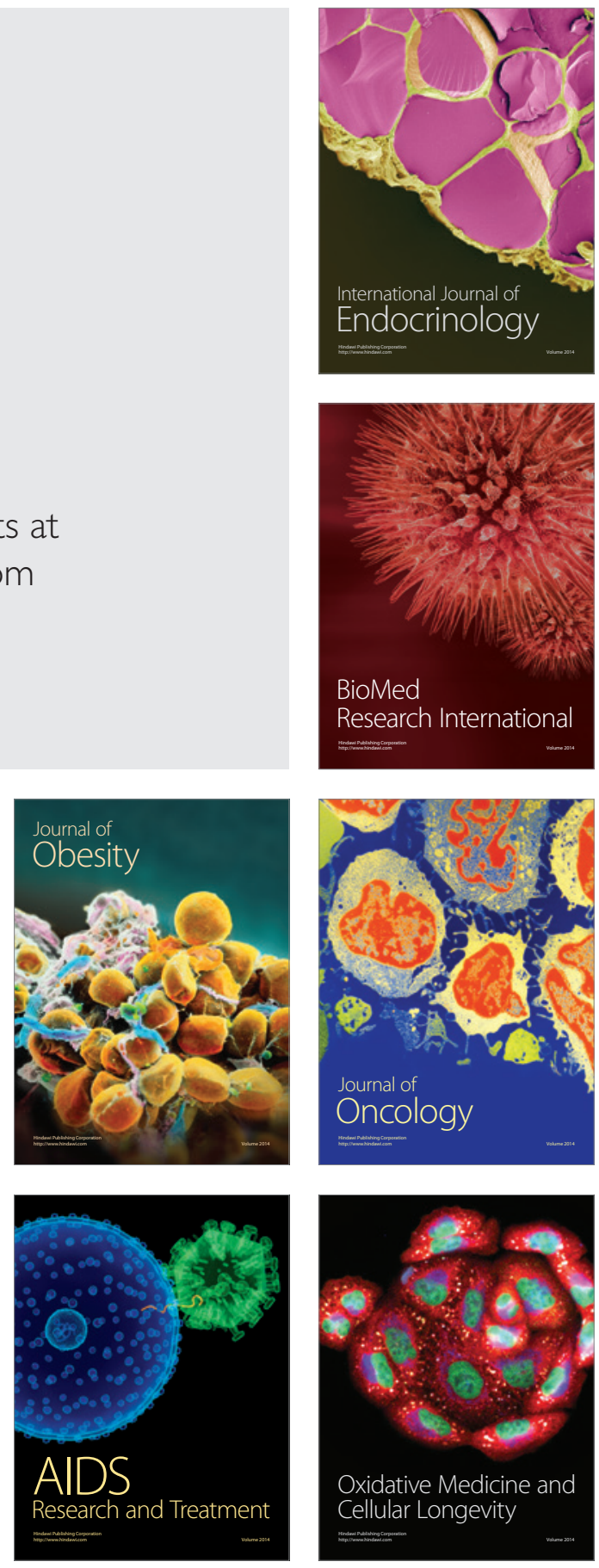